\title{
Cloning and hypothalamic distribution of the chicken thyrotropin-releasing hormone precursor cDNA
}

\author{
Kristien Vandenborne, Simon A Roelens, Veerle M Darras, \\ Eduard R Kühn and Serge Van der Geyten
}

Laboratory of Comparative Endocrinology, Zoological Institute, K U Leuven, Naamsestraat 61, B-3000 Leuven, Belgium

(Requests for offprints should be addressed to S Van der Geyten; Email: serge.vandergeyten@bio.kuleuven.ac.be)

\begin{abstract}
In this paper we report the cloning of the chicken preprothyrotropin-releasing hormone $(\mathrm{TRH}) \mathrm{cDNA}$ and the study of its hypothalamic distribution. Chicken preproTRH contains five exact copies of the TRH progenitor sequence (Glu-His-Pro-Gly) of which only four are flanked by pairs of basic amino acids. In addition, the amino acid sequence contains three sequences that resemble the TRH progenitor sequence but seem to have lost their TRH-coding function during vertebrate evolution. The amino acid sequence homology of preproTRH between different species is very low. Nevertheless, when the tertiary structures are compared using hydrophobicity plots, the resemblance between chicken and rat preproTRH is striking. The cloning results also showed that the
\end{abstract}

chicken preproTRH sequence includes neither a rat peptide spacer 4 (Ps4) nor a Ps5 connecting peptide. Comparison of the cDNA sequence with the chicken genome database revealed the presence of two introns, one in the $5^{\prime}$ untranslated region, and another downstream from the translation start site. This means that the gene structure of chicken preproTRH resembles the gene stucture of this precursor in mammals. Based on the cDNA sequence, digoxigenin-labelled probes were produced to study the distribution of preproTRH in the chicken brain. By means of in situ hybridization, preproTRH mRNA was detected in the chicken paraventricular nucleus (PVN) and in the lateral hypothalamus (LHy).

Journal of Endocrinology (2005) 186, 387-396

\section{Introduction}

Thyrotropin-releasing hormone (TRH) is a neuroactive tripeptide (L-pyroglutamyl-L-histidyl-L-prolinamide; pGluHis-ProNH ${ }_{2}$ ), that was originally isolated from porcine and ovine hypothalami as a first hypothalamic releasing hormone (Schally et al. 1969, Burgus et al. 1970). Like other regulatory peptides, TRH is synthesized as a high molecular weight precursor. The first TRH precursor cDNA clones were isolated from the skin of the frog Xenopus laevis (Richter et al. 1984, Kuchler et al. 1990). In addition, a smaller TRH precursor cDNA was isolated from the brain of this species (Bulant et al. 1992b). The latter study also revealed the characteristics of the gene encoding this preproTRH. In the meantime, research on this topic had spread out to other species. This led to the elucidation of the preproTRH cDNA structure in rat (Lee et al. 1988), human (Yamada et al. 1990), mouse (Satoh et al. 1992) and sokeye salmon (Ohide et al. 1996). In general, the preproTRH coding sequence always codes for more than one TRH progenitor sequence (Glu-His-Pro-Gly), each one flanked by dibasic cleavage sites. Within different species, preproTRH differs in the number of TRH copies (five in rat (Fig. 1) and mouse, six in human, seven in Xenopus and eight in salmon) and in the amino acid sequences of the so-called 'cryptic peptides' or 'peptide spacers' (Ps), which are set free when preproTRH is proteolytically processed. The search for the biological function of these connecting peptides started years ago and focussed mainly on rat Ps4 or preproTRH-(160-169) (Bulant et al. 1990, 1992a, Ladram et al. 1992, 1994, Carr et al. 1993, Pekary 1998) and rat Ps5 or preproTRH-(178-199) (Liao et al. 1988a,b; Roussel et al. 1994, Redei et al. 1995, McGivern et al. 1997) (Fig. 1). Research in chicken suggested that also in the central nervous system of this species, peptides like Ps4 and Ps5 are present and exert an endocrine function (Harvey 1990, Harvey \& Cogburn 1996, Harvey et al. 1996). However, for Ps4, no binding sites were detected on the chicken pituitary (Geris et al. 2000). In order to verify whether both Ps4 and Ps5 exist in the chicken brain as a part of the preproTRH molecule, we set out to elucidate the sequence of the chicken TRH precursor.

Immunocytochemical studies in rats demonstrated preproTRH-containing neurons in the parvocellular portion of the paraventricular nucleus (PVN), the dorsomedial nucleus, the arcuate nucleus and regions of the preoptic nucleus. In addition, preproTRH-immunoreactive neurons were found in the rat telencephalon, mesencephalon, 


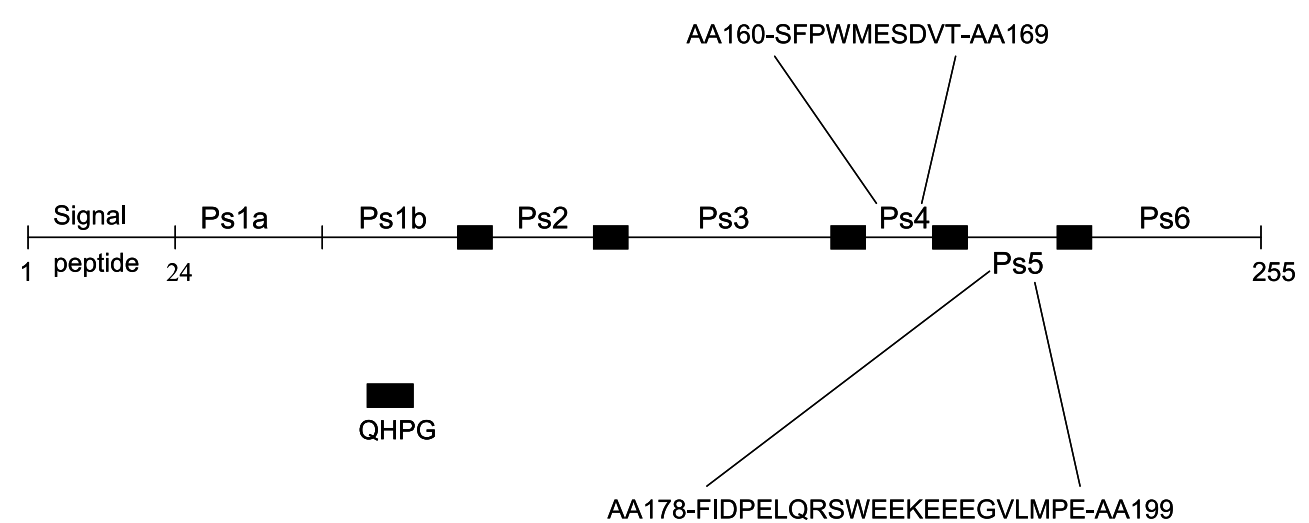

Figure 1 Schematic representation of rat preproTRH. Black boxes indicate TRH progenitor sequences (adapted from Lee et al. 1988).

metencephalon and myelencephalon (Jackson et al. 1985, Lechan et al. 1986). Results of immunocytochemical studies in hypothyroid rats suggested that only the TRH cells in the parvocellular portion of the PVN are involved in the regulation of the hypothalamic-pituitary-thyroid (HPT) axis (Nishiyama et al. 1985). Data on the distribution of the preproTRH mRNA-containing cells in the human and rat hypothalamus generally agreed with immunocytochemical data (Segerson et al. 1987, Guldenaar et al. 1996, Fliers et al. 1998). The distribution of TRH peptide in the chicken brain has also been studied in detail via immunocytochemistry (Józsa et al. 1988) and radioimmunoassays (Geris et al. 1999). However, there were no data available on the hypothalamic preproTRH gene expression in the chicken brain. With the elucidation of the chicken preproTRH cDNA sequence reported in this paper, we were able to investigate the hypothalamic distribution of the TRH precursor.

\section{Materials and Methods}

Animals

All studies were conducted on 9-day-old Ross broiler chickens (Avibel, Halle-Zoersel, Belgium) purchased as 1-day-old chicks of both sexes. Chickens were kept under a photoperiod of $14 \mathrm{~h}$ light: $10 \mathrm{~h}$ darkness and fed a commercial mixed diet (Hendrix, Merksem, Belgium). The K U Leuven Ethical Committee for Animal Experiments approved all experimental protocols.

In silico analysis of the chicken preproTRH gene structure

We used the first draft of the chicken genome project (http://pre.ensemble.org/Gallus_gallus), released 1 March 2004 and published December 2004 (Wallis et al. 2004), for a blast search with the TRH peptide sequence. This resulted in five hits in the same contig sequence
(Contig49.130·1·79290) located on chromosome 12. The primer design for the molecular cloning of the preproTRH cDNA via RT-PCR was based on this contig nucleotide sequence.

\section{$R N A$ extraction and RT-PCR}

Total RNA was extracted from the diencephalon of 9-day-old chicks using the Total RNA Isolation System (Promega) for use in RT-PCR. First, $1 \mu \mathrm{g}$ RNA was denatured at $75{ }^{\circ} \mathrm{C}$ for $5 \mathrm{~min}$ in the presence of an oligo(dT)-primer (Roche). Reverse transcription was performed at $42{ }^{\circ} \mathrm{C}$ for $60 \mathrm{~min}$, using $2.5 \mathrm{U}$ avian myeloblastosis virus reverse transcriptase (AMV-RT; Roche). The subsequent PCR amplification was conducted using $5 \mu \mathrm{l}$ of the reverse transcription reaction. The total PCR reaction mix $(20 \mu \mathrm{l})$ contained PCR buffer $(10 \mathrm{mM}$ Tris$\mathrm{HCl} \mathrm{pH} 9 \cdot 0,1.5 \mathrm{mM} \mathrm{MgCl}_{2}, 50 \mathrm{mM} \mathrm{KCl}, 0 \cdot 1 \%$ Triton $\mathrm{X}-100$ and $0 \cdot 01 \%$ gelatin), $1 \mathrm{mM}$ of each dNTP, $1 \mu \mathrm{M}$ of each primer and $1 \mathrm{U}$ SuperTaq DNA polymerase. After denaturation at $94{ }^{\circ} \mathrm{C}$ for $5 \mathrm{~min}, 30$ thermocycles of $45 \mathrm{~s}$ at $94{ }^{\circ} \mathrm{C}, 1 \mathrm{~min}$ at $55^{\circ} \mathrm{C}$ and $2 \mathrm{~min}$ at $72{ }^{\circ} \mathrm{C}$ were conducted and followed by a final elongation step at $72{ }^{\circ} \mathrm{C}$ for $5 \mathrm{~min}$.

\section{Primer design}

Primers were based on the nucleotide sequence near the TRH progenitor sequences found by searching the chicken genome database. Using the combination of a first primer couple (sense: 5'-ATTAAACATGCCTCTGCC ACA-3', bp 198-217 (Fig. 2); antisense: 5'-AAACAATT ACTTTCTCATTCCTCTG-3', bp 773-797 (Fig. 2)) we generated a $600 \mathrm{bp}$ fragment, and using a second primer couple (sense: 5'-ATCACAATGCCATCTATC CAGCTG-3', bp -6 to 18 (Fig. 2); antisense: 5'-TGT TTCATTCTCCCATGCTG-3', bp 755-774 (Fig. 2)) a $780 \mathrm{bp}$ cDNA fragment was obtained. The cDNA fragments were purified from an agarose gel using the QIAEX II gel extraction kit (Qiagen) and then subcloned into the 


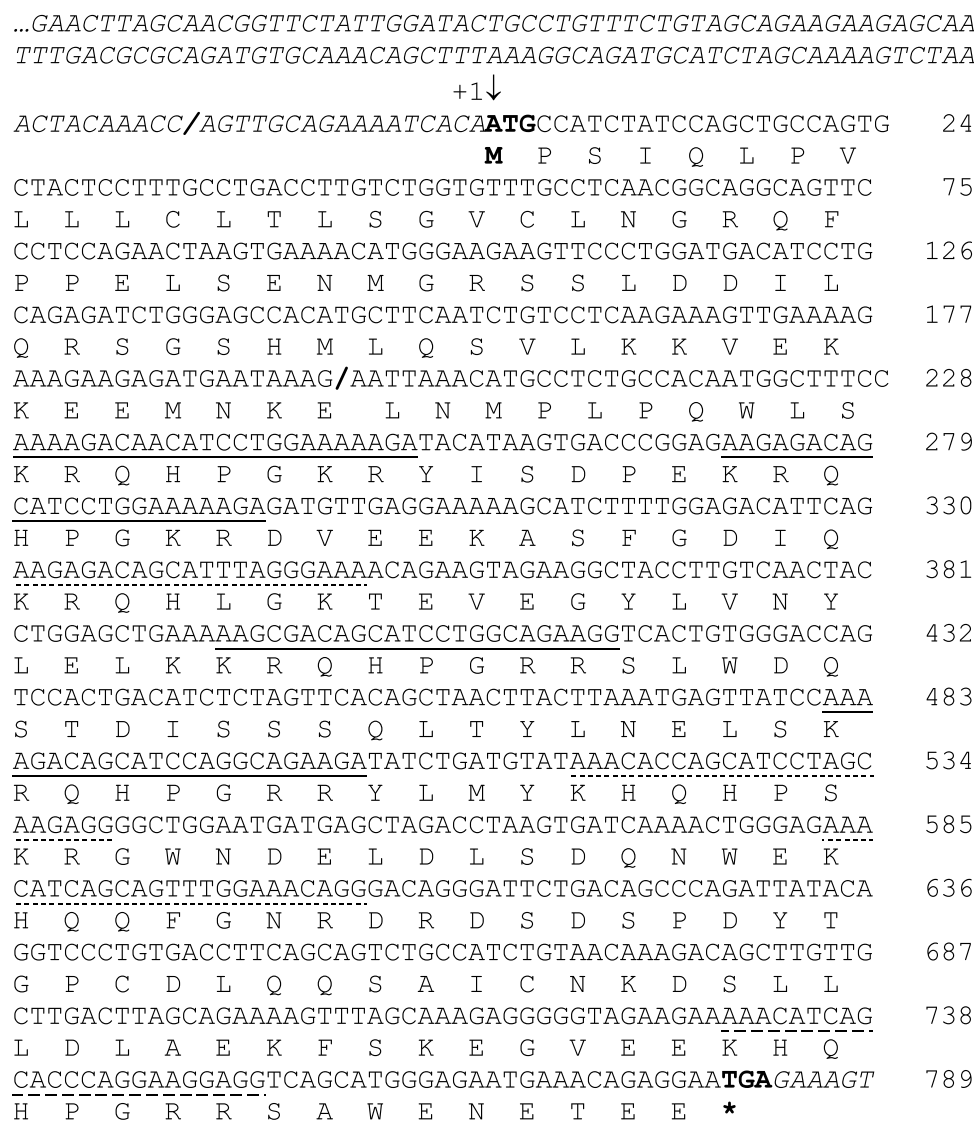

AATTGTTTATCATTTCAATATGGTGAAGTAAAATGACAGAACACTAAAAAACTCTGTCTGCTCC CTTCTGGCTTCCTGCTGCTGACCTCCAAACCTATCTTTCAGTGAGTGAGCGTCCTCATTTAAAC TAATGGCTTTGTCATGCACCTGAAGTAAAGGAACTGAGAAACACTCAGCTGAATGGACTCAGCA AGTAGTGAGTTTTCAACTCCCTCACTCTGTGAAATTAAGAGTAGTCAGTTCCTTTACGAGCCCA GAATATTCATGTTATGTGTGAACTAGCACATGCTCTTTAATACCTCTTCTGATGTTACTACAGT AATTATATTGTTTCCTCTCGTGTCAGTGAAATCAGTACAATCGGGGAAAAAAAAGAACATATGC AAATGATTTCAAAATGAAACTGAGTGGGTTTTCAATTCTAGATGATACGTTATGAGACCTCCTG TCTACAATCTATCCAACAATAGACTGACAGATAGGGAGACTGTCCACTGCGCAGATCAATGCTG GCTTCATACTTTGACTCAGAACTAAAAAACAAAAATTTCATCTAGAAGCTGCAAAGTGCAAAGG GTTAGTGAATCCCAGAGCAACTCAACCTCCCAGTTATGACCTTGGCCACGTACACCTCACCTTA GCCTGATGTGCTAACATTTCAGTCATTCTCCTTGAAATATGCCTTCCCCTTAGATGTGTAAAAT GGAAACAAAAAAATCTTTTCTTCTGATAGGATTTCTAATTTCTCCCCCTCAAAGAAATGTTTTC CCTTCTGTGATGAGAGTCACAAAAGTGTTTATTTGATATGAATGACTCAATAAACATAAGAAGT AAAGTCTGTGTGTCCTTACAGGTTGCATATTACAGGTTGTACTGTAATAAGAGAAAAAAAAACA GTCCAAGCTAAGTCAAAATAAATAAATGAACACTAGGAGATACTTTTCTAGGTGGAAGCTTCTT GCATGCTGGTCAGCCCTTGTTTATTTGTAAAACTGGTCTGCTAGTGCAGTAGCAAATAGATATA TTCCCCTATGAAATCCCTTCTGTAGACACTCAGGAACAGGCAACTGGGTAAGCCATAACACTTT GTCACCCAGTTCATAAGGAACTTCAGTGTTGAGTCTGATCTGGCAGGCAAAACTGGTTAGGAGC AGACTTGTTTTAAACAAAAGAAGAAAGGTTGATTGATCTACGCTGCCCAAACCTTCTGAGTTCC ATAACCTTTTGCAACATAGTTATAGAACAAGTCATGCTAGCATGCAAGTCACTGCAGAGAGAAA TGAGAATTCAGTGGTCTTCTGCCATATGCCTGGTAAATAGCTTTGCTGTAGCTGAGCTTTACTA GATGTAATTGATTACTATGCATGCACACATACACATAGCTCTTAGAATTGTATAAACAATCATT TATTTGAAATTAAAATACCTCTATATATATTTGCATGGTCTGCTAAAAAAAAAAAAAAAAAAAA AAAAAAAA

Figure 2 Nucleotide and amino acid sequence of the chicken TRH precursor, as obtained via RT-PCR, 5' and 3' RACE. The stop codon and the start codon (designated as ' $+1^{\prime}$ ) are printed in bold. Sequences coding for TRH flanked with dibasic cleavage site are indicated by a solid line, sequences resembling TRH coding sequences are indicated with dotted lines. The dashed line indicates the TRH coding sequence that lacks a dibasic cleavage site. Nucleotides belonging to the 5' UTR and 3' UTR are printed in italic. The putative polyadenylation signal in the $3^{\prime}$ UTR is printed in bold. The exon-intron-exon boundaries are indicated with a solidus. 
pCRII-TOPO vector using the TOPO-TA cloning kit (Invitrogen). The nucleotide sequence was determined by automatic sequencing using the ABI PRISM 310 genetic analyzer (Applied Biosystems, Belgium).

\section{Rapid amplification of $c D N A$ ends (RACE)}

In order to reveal the complete cDNA sequence both $5^{\prime}$ and 3' RACE were carried out using the SMART RACE cDNA amplification kit (BD Biosciences, CA, USA). Primers used were based on the known nucleotide sequence obtained via RT-PCR. 5' RACE was carried out with the antisense primer $5^{\prime}$-CCCAGATCTCTGC AGGATGTCATCCAGGG-3' (bp 110-138; Fig. 2) and $3^{\prime}$ RACE was carried out with three different sense primers: 5'-CAGCACCCAGGAAGGAGGTCAGCAT GGG-3' (bp 736-763; Fig. 2), 5'-CCCTTCTGGCT TCCTGCTGCTGACCTCC-3' (bp 852-878; Fig. 2) and 5 '-CTCAACCTCCCAGTTATGACCTTGGCC ACG-3' (bp 1358-1387; Fig. 2).

\section{Verification of the intron sequence}

When comparing the nucleotide sequence obtained with RT-PCR and RACE with the sequence from the genome database, two putative introns were discovered. In order to verify the exon-intron boundaries and the intron nucleotide sequences, genomic DNA was extracted from diencephalon tissue using the GenElute Mammalian Genomic DNA Kit (Sigma-Aldrich). The genomic DNA was used as a template in a PCR reaction (protocol as described above) using primers located around both putative introns. For the intron located in the $5^{\prime}$ untranslated region (UTR) we used sense primer 5'-GACGCGCAGA TGTGCAAACAGC-3' (bp -82 to -61 ; Fig. 2) and antisense primer $5^{\prime}$-CCCAGATCTCTGCAGGATGTC ATCCAGGG-3' (bp 110-138; Fig. 2). For the intron located in the coding region, we used sense primer 5'-ATCACAATGCCATCTATCCAGCTG-3' (bp - 6 to 18; Fig. 2) and antisense primer 5'-TGTTTCATTCT CCCATGCTG-3' (bp 755-774; Fig. 2).

\section{Tissue sectioning}

The complete chicken brain was dissected from 9-day-old chicks and fixated in a buffered $4 \%$ paraformaldehyde solution for 24-48 h. Tissues were then placed in buffered sucrose solutions with increasing concentration (10-30\%) and frozen at $-80{ }^{\circ} \mathrm{C}$ until sectioning using a cryostat. In situ hybridization was performed on coronal sections at $30 \mu \mathrm{m}$ intervals through the chicken brain. The stereotaxic brain atlas (Kuenzel \& Masson 1988) was used to recognize different regions of the brain. Sections were placed on Superfrost slides (MLS, Menen, Belgium) and stored at $-20{ }^{\circ} \mathrm{C}$.

\section{Production of digoxigenin (DIG)-labelled riboprobes}

The $600 \mathrm{bp}$ PCR fragment, obtained after RT-PCR (sense primer: bp 198-217 (Fig. 2); antisense primer: bp 773-797 (Fig. 2)) was subcloned in a pCRII-TOPO plasmid vector (Invitrogen) and used for bacterial transformation. Plasmid DNA was isolated using the High Pure Plasmid Isolation Kit (Roche). For the construction of the sense probe, the plasmid was digested with SacI (Roche), while for the antisense probe the plasmid was digested using ApaI (Roche). Riboprobes were transcribed from $1 \mu \mathrm{g}$ of the linearized plasmids in the presence of DIG RNA labelling mix (Roche) and 20 U RNA polymerase (Roche), Sp6 for antisense and T7 for sense probes. The quality of the labelling was verified by means of a spotting test, where $1 \mu \mathrm{l}$ of five different probe concentrations (ranging from 300 to $3 \mathrm{pg} / \mu \mathrm{l}$ ) were spotted on a Hybond $\mathrm{N}+$ nylon membrane (Amersham). The spots were visualized using antibodies against DIG (Roche) and the nitro blue tetrazolium/5-bromo-4-chloro-3-indolylphosphate (NBT/BCIP) detection system (Roche).

\section{In situ hybridization}

The cryostat sections were pretreated in $4 \%$ paraformaldehyde solution $(10 \mathrm{~min})$, PBS $(3 \times 5 \mathrm{~min}), 0 \cdot 2 \mathrm{M} \mathrm{HCl}$ (10 min), triethylamine (TEA) buffer with $0 \cdot 25 \%$ acetic anhydride (10 min), PBS $+1 \%$ Triton X-100 (TX) (30 min) and PBS $(3 \times 5 \mathrm{~min})$. Subsequently, the slices were prehybridized for $2 \mathrm{~h}$ at room temperature in hybridization buffer $(50 \%$ formamide, 10\% dextran sulphate, $5 \%$ Denhardts, $0.625 \mathrm{M} \mathrm{NaCl}, 0.2 \mathrm{M} \mathrm{Na}$-PIPES $\mathrm{pH} 6.8$ in $50 \mathrm{ml}$ diethylpyrocarbonate-treated distilled water) containing 0.05 M dithiothreitol (DTT), $250 \mu \mathrm{g} / \mu \mathrm{l}$ denatured herring sperm and $250 \mu \mathrm{g} / \mu \mathrm{l}$ yeast tRNA. Afterwards, the sections were hybridized under coverslips overnight at $80^{\circ} \mathrm{C}$ in the same hybridization buffer containing $200 \mathrm{ng} / \mathrm{ml}$ DIG-labelled RNA probe. After hybridization the sections were washed for $45 \mathrm{~min}$ at $72{ }^{\circ} \mathrm{C}$ in $0.2 \times \mathrm{SSC}, 2 \times 5 \mathrm{~min}$ in $0.2 \times \mathrm{SSC}$ at room temperature and $3 \times 5 \mathrm{~min}$ in $\mathrm{PBS}+0 \cdot 1 \% \mathrm{TX}$. Thereafter, the sections were incubated for at least $1 \mathrm{~h}$ with PBS $+0 \cdot 1$ TX containing 4\% BSA and $0 \cdot 1 \mathrm{M}$ lysine to reduce background signal. Per section, $0.5 \mathrm{ml}$ anti-DIG antibodies $(1 / 5000$, in PBS $+0 \cdot 1 \%$ TX + BSA) were added and incubated for $2 \mathrm{~h}$ at room temperature and overnight at $4{ }^{\circ} \mathrm{C}$. The alkaline phosphatase signal was detected using the NBT/BCIP chromogen system (Roche).

\section{Results and Discussion}

\section{Molecular cloning of chicken preproTRH}

Using RT-PCR and RACE we were able to construct a 2412 bp cDNA fragment containing the $5^{\prime}$ and $3^{\prime}$ untranslated regions together with the complete coding region for 


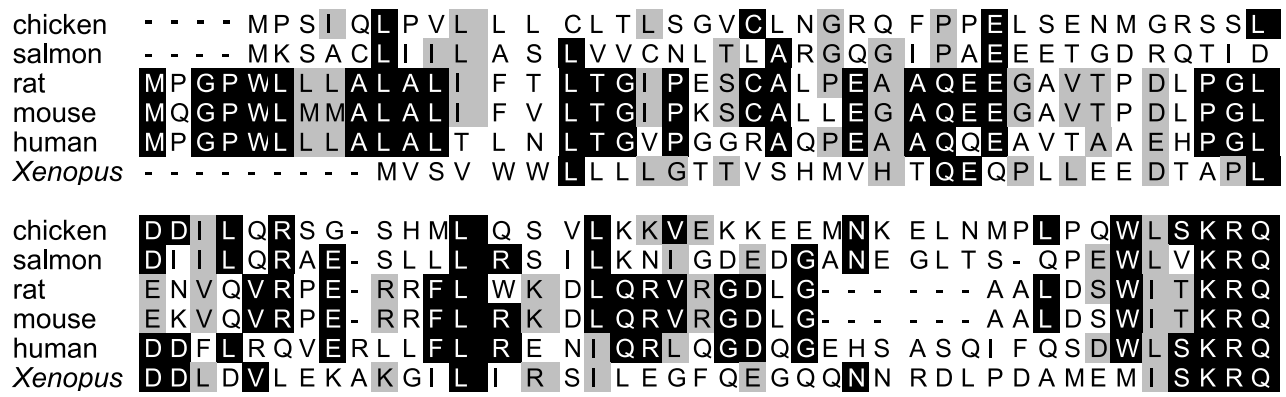

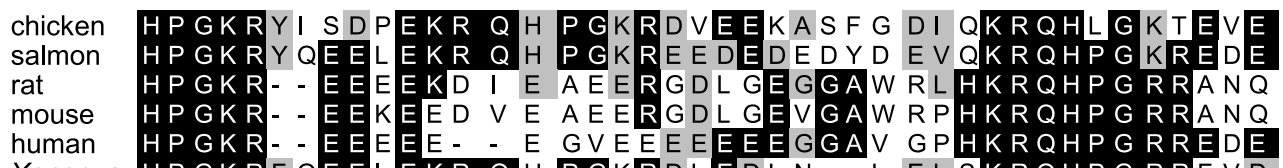

Xenopus HPGKRFQEEI EKR QH PGKRDLEDLN- - L ELSKRQHPGRRFVD

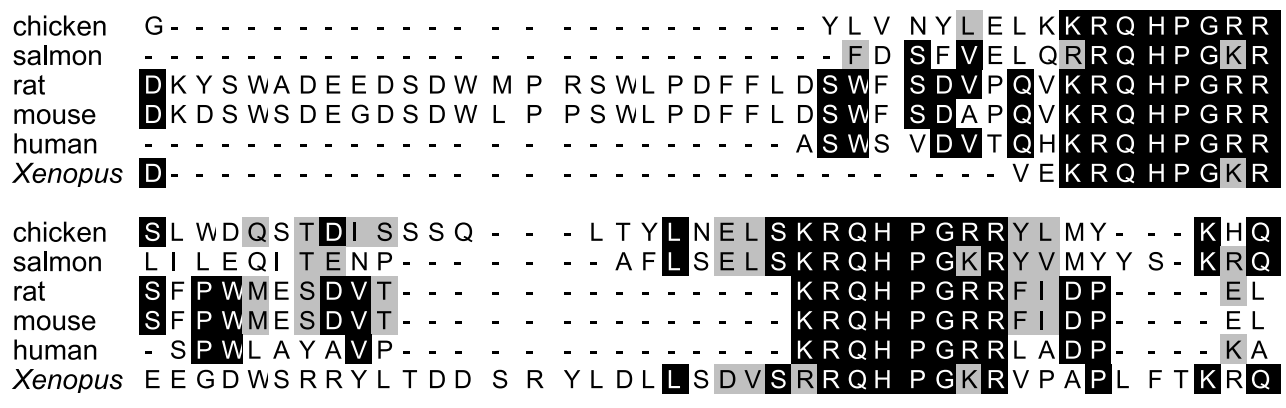

chicken HPSKRGWNDELD- L S DQ- NWEKHQQFGN RDRDSDSPDYTG- salmon HPGRREVDDESD-A G DLRELEKRQHPGK RYLDNTSPDLGANS rat QRSWEEKEGE- - - - GVLMPEKRQHPGK RALGHPCG - - - . mouse QRSWEETEGEE - - - - GGLMPEKRQHPGK RAVGHPCG - - - . human QRS WEEEEEEEE - R E EDL MPEKRQHPGK RALGGPCG - . - . Xenopus HPGKRVTEEEGDT E F ESKEVGKRQHPGK RYDPCEGP - . . . . -

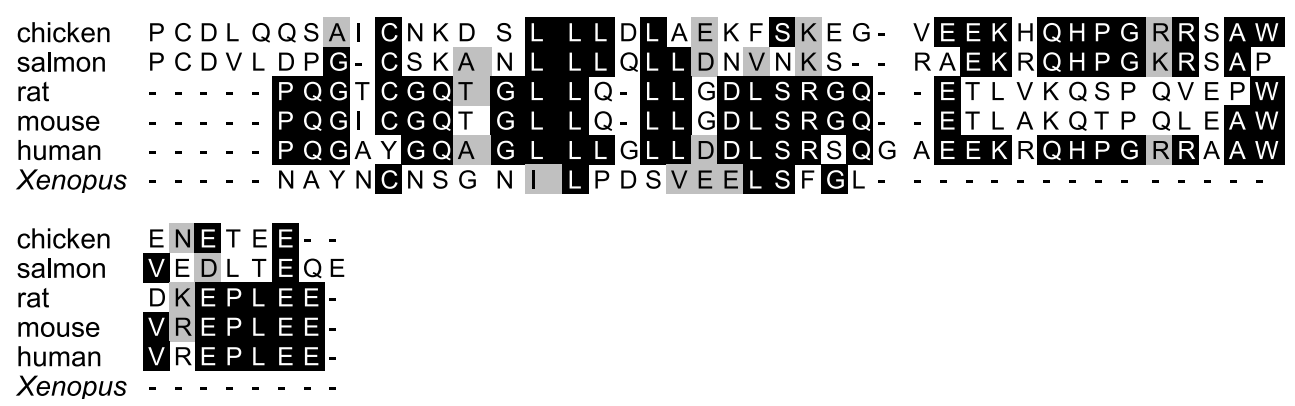

Figure 3 PreproTRH amino acid sequence alignment of chicken, salmon, rat, mouse, human and Xenopus laevis. Identical amino acids have a black background, similar amino acids have a gray background. The alignment was carried out using the Clustal-W software (http://clustalw.genome.jp) together with the Boxshade software: (http://bioweb.pasteur.fr/seqanal/interfaces/boxshade-simple.html).

chicken preproTRH (Fig. 2). This sequence has been submitted to the EMBL database under accession number AJ703806. As shown in Fig. 2, the deduced amino acid sequence contains five exact copies of the TRH progenitor sequence. On top of these five copies, the sequence contains three copies that more or less resemble the progenitor sequence. It is possible that these sequences once coded for TRH, but that somewhere during evolution mutations have occurred. It is surprising that such mutated TRH sequences do not occur in known preproTRH sequences from other species. Of the five exact TRH peptide sequences, only four are flanked by prohormone convertase cleavage sites (Lys-Arg or ArgArg). The fifth TRH peptide is flanked at the N-terminus by Lys-His, which is not recognized by the currently known prohormone convertases, and can therefore not 

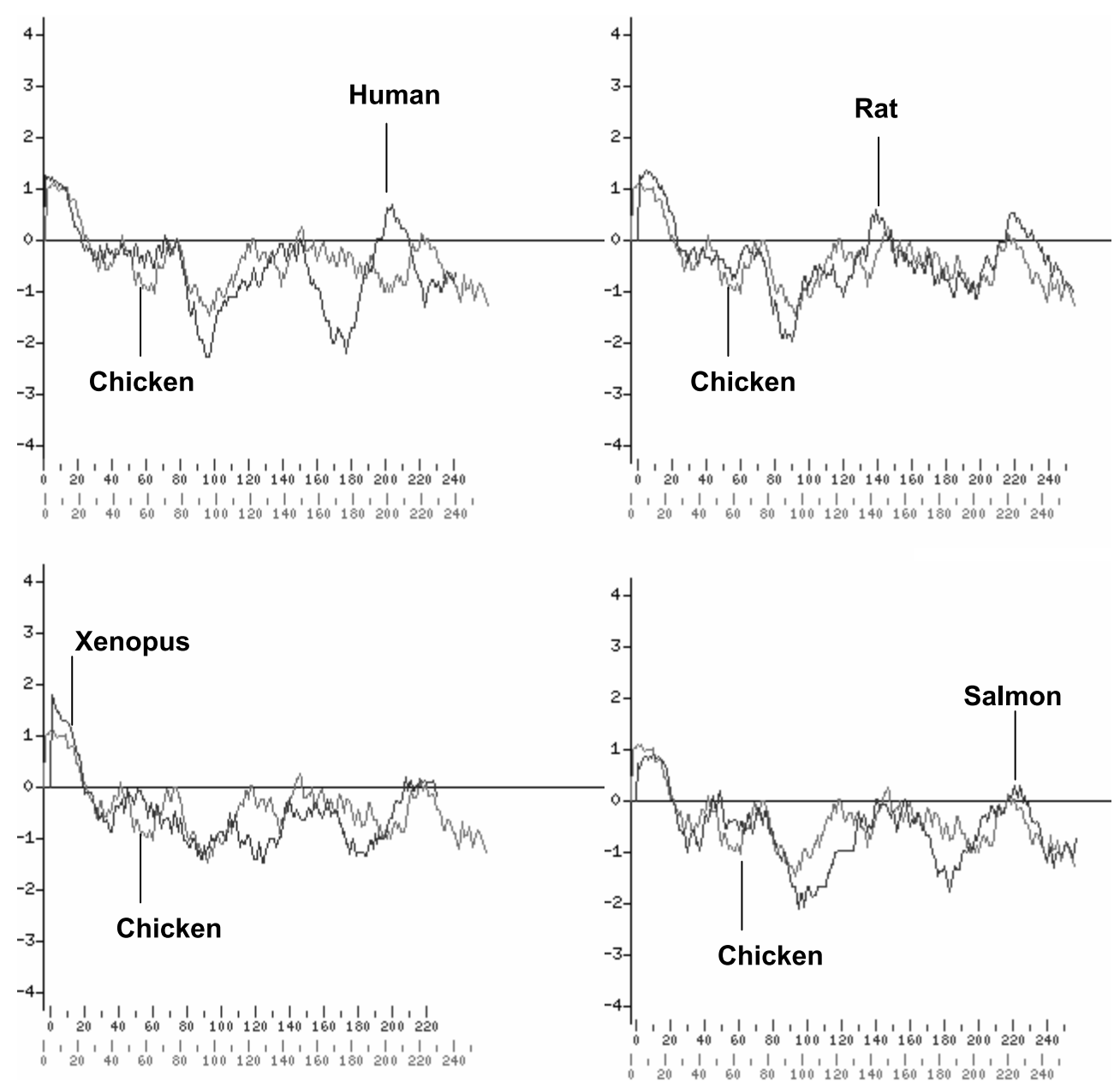

Figure 4 Comparison of the hydrophobicity plots of chicken preproTRH with human, rat, salmon and Xenopus laevis preproTRH. This figure was constructed using the following software: http://bioinformatics.weizmann.ac.il/hydroph/cmp hydph.html.

be proteolytically cleaved (Barbetti et al. 1990). We can not exclude the possibility that, in the chicken, a proteolytic enzyme exists that recognizes Lys-His as a cleavage site, although so far this has never been described in the literature. An extra TRH peptide that is probably not proteolytically cleaved, has not been detected in other known preproTRH sequences. We can conclude that the gene coding for the chicken TRH precursor has mutated frequently since the diversion of birds from other vertebrates.

Figure 3 shows the result of a homology study between the primary structures of chicken, human, rat, Xenopus laevis and sockeye salmon preproTRH. It seems that the primary preproTRH structures are not very well conserved between species. The TRH progenitor sequence is always the same, but since this sequence only counts for four amino acids, the connecting peptides are more important for the general homology. With the reports on the mammalian preproTRH sequences, it had already been demonstrated that the sequence homology of these connecting peptides was very low, even between rat and human. Our cloning results show that no Ps4- or Ps5-like peptide is present in the chicken preproTRH sequence. In addition, a blast search for peptides resembling Ps 4 and Ps5 in the chicken genome database did not indicate the existence of these peptides in this species. Together with the knowledge that no binding sites for rat Ps4 were found in the chicken pituitary (Geris et al. 2000), we postulate that the biological functions proposed for these peptides in the chicken (Harvey 1990, Harvey \& Cogburn 1996, Harvey et al. 1996, Geris et al. 2000) were actually non-physiological. However, since immunoreactivity for Ps4 was found in the paraventricular region and in the median eminence of the chicken brain using an antiserum against rat Ps4 (Harvey et al. 1996), we can not exclude the possibility that a peptide resembling Ps4 exists in the 


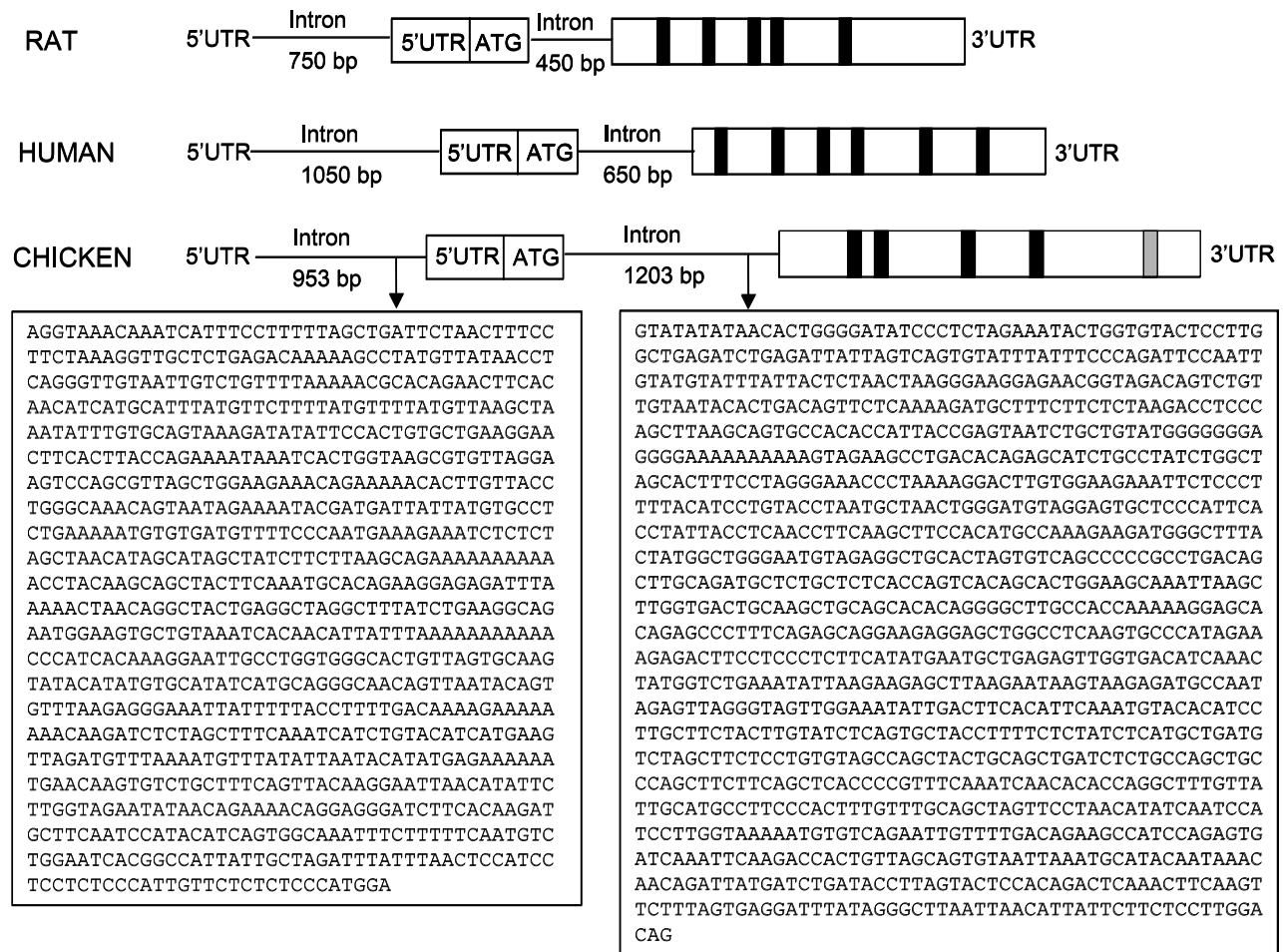

Figure 5 Schematic representation of the rat and human preproTRH gene, compared with the chicken preproTRH gene. For the chicken, the nucleotide sequences of both introns are included. Black boxes indicate the TRH progenitor sequences, the gray box in the chicken sequence indicates the sequence that codes for the TRH progenitor sequence, but lacks the $5^{\prime}$ dibasic cleavage site.

central nervous system of the chicken and that this peptide is responsible for some of the biological functions described for Ps4.

Using the Hopp-Woods scale (Hopp \& Woods 1981), hydropathy plots were constructed, in order to compare the tertiary structures of the different preproTRH proteins. From Fig. 4 it is clear that the plots for chicken and rat preproTRH show a very high degree of similarity, which indicates that the three-dimensional structures of these two proteins are very much alike. The resemblance to the other three preproTRH proteins is less, although the overall structure remains very similar: a hydrophobic sequence (probably the signal sequence) followed by a hydrophilic protein with one or two more hydrophobic regions. These results are in accordance with findings from Ohide et al. (1996), who stated that the three-dimensional structures of TRH precursors are highly conserved, although the primary structures of these proteins have diverged throughout vertebrate evolution.

When comparing the cDNA sequence with the gene sequence found on chromosome 12 in the chicken genome database, the presence of two introns becomes apparent. A first intron is situated in the $5^{\prime}$ UTR, a second intron is located downstream from the translation start site. The intron-exon boundaries and the nucleotide sequence of both introns were confirmed by PCR on genomic DNA from chicken diencephalon (Fig. 5). The presence and location of these introns is in accordance with the preproTRH gene structures from mammalian species, which also contain two introns in the same regions of the gene (Fig. 5).

\section{In situ hybridization}

The cloning of the chicken preproTRH cDNA allowed in situ hybridization experiments in order to study the distribution of this precursor's mRNA in the chicken brain. Figures 6 and 7 show the results of the in situ hybridization using DIG-labelled probes. Panels A and B represent the signal using the antisense probe, panel C shows the result of hybridization with the sense probe as a negative control. The only TRH precursor mRNAcontaining cells were found in the PVN (Fig. 6) and the lateral hypothalamic area (LHy) (Fig. 7). These results correlate with the distribution of preproTRH mRNA in the mammalian hypothalamic region (Segerson et al. 1987, Guldenaar et al. 1996, Fliers et al. 1998). In addition, these researchers found a small number of preproTRH mRNAcontaining cells in the human and rat suprachiasmatic nucleus (SCN). Immunocytochemical experiments with 

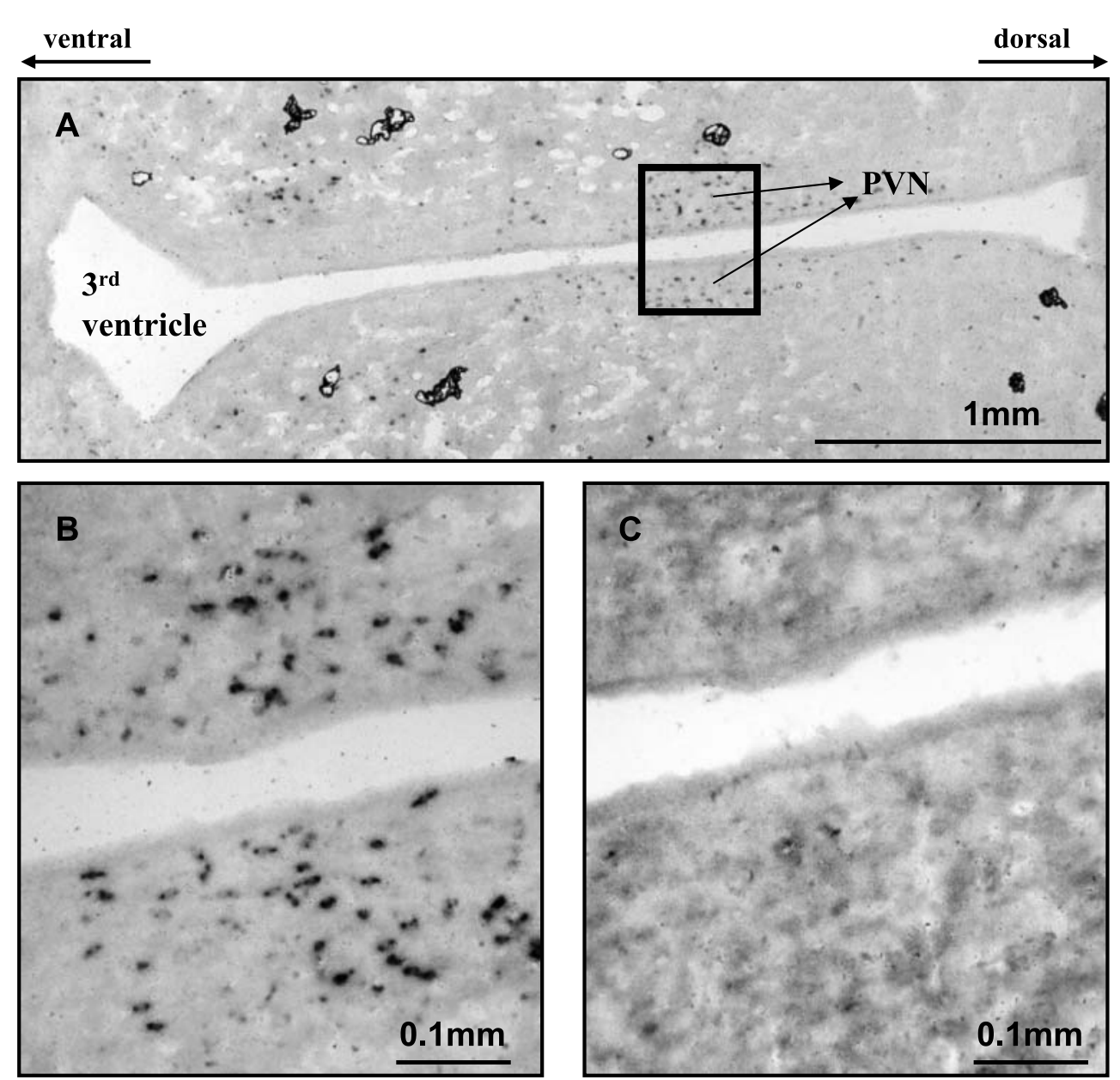

Figure 6 Distribution of preproTRH mRNA-containing cells in the PVN of the chicken hypothalamus. (A) An overview of the result from hybridization with the antisense probe; (B) an enlargement of the boxed area in panel A. (C) The same area as in panel B, after hybridization with the sense probe (as a negative control).

antibodies against TRH on chicken brain tissue revealed a large number of immunoreactive perikarya in the parvocellular portion of the PVN and in the LHy (Józsa et al. 1988). Some scattered immunopositive cells were also detected in the SCN. However, our hybridization experiment did not demonstrate any preproTRH mRNA in the SCN. Although it is possible that the sensitivity of our technique is not high enough to detect a small amount of mRNA in the SCN, an alternative explanation is that, in chickens, preproTRH is not synthesized in the SCN but transported towards this region, explaining the presence of previously reported immunopositive neurons. The in situ hybridization experiments of other regions of the chicken brain (telencephalon, mesencephalon and cerebellum) did not show any positively stained cells (results not shown). It is possible that the lack of signal might be a result of the low sensitivity of our technique, since experiments in rats showed the presence of preproTRH mRNA in telencephalon and mesencephalon (Segerson et al. 1987) and immunocytochemistry of the chicken brain showed the presence of biologically active TRH in extrahypothalamic regions of the brain (Józsa et al. 1988).

In summary, we report the cloning of the chicken preproTRH cDNA and its hypothalamic distribution. The chicken preproTRH contains five exact copies of the TRH progenitor sequence of which only four are flanked by pairs of basic amino acids. The amino acid sequence homology between different species is very low. Nevertheless, when the tertiary structures are compared using the hydrophobicity plots of preproTRH in different species, the general resemblance between chicken and rat TRH precursor is striking. By means of in situ hybridization, preproTRH mRNA was detected in the chicken PVN and the LHy. 


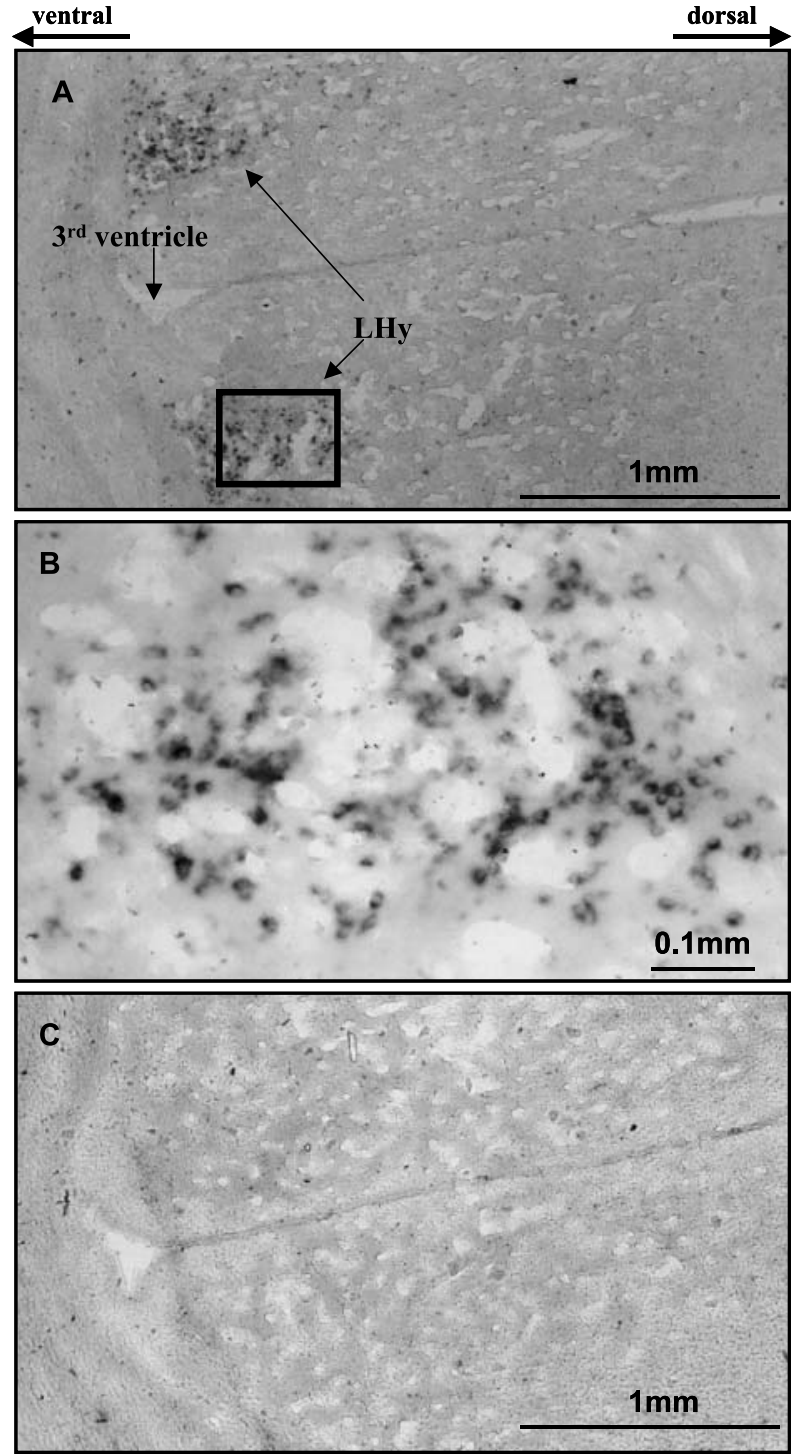

Figure 7 Distribution of preproTRH mRNA-containing cells in the LHy of the chicken. (A) An overview of the result from hybridization with the antisense probe; (B) an enlargement of the boxed area in panel A. (C) The same area as panel A, after hybridization with the sense probe (as a negative control).

\section{Funding}

This research was partly financed by the Fund for Scientific Research Flanders (FWO; grants G.0360.00 and G.0402.05). K V was financially supported by the IWT-Vlaanderen (Institute for the Promotion of Innovation through Science and Technology in Flanders). S V and S R were supported by the FWO. The authors declare that there is no conflict of interest that would prejudice the impartiality of this scientific work.

\section{References}

Barbetti F, Raben N, Kadowaki T, Cama A, Accili D, Gabbay KH, Merenich JA, Taylor SI \& Roth J 1990 Two unrelated patients with familial hyperproinsulinemia due to a mutation substituting histidine for arginine at position 65 in the proinsulin molecule: identification of the mutation by direct sequencing of genomic deoxyribonucleic acid amplified by polymerase chain reaction. Journal of Clinical Endocrinology and Metabolism 71 164-169.

Bulant M, Roussel JP, Astier H, Nicolas P \& Vaudry H 1990 Processing of thyrotropin-releasing hormone prohormone (proTRH) generates a biologically active peptide, prepro-TRH-(160-169), which regulates TRH-induced thyrotropin secretion. PNAS $\mathbf{8 7}$ 4439-4443.

Bulant M, Ladram A, Montagne JJ, Delfour A \& Nicolas P 1992a Isolation and amino acid sequence of the TRH potentiating peptide from bovine hypothalamus. Biochemical and Biophysical Research Communications 189 1110-1118.

Bulant M, Richter K, Kuchler K \& Kreil G $1992 b$ A cDNA from brain of Xenopus laevis coding for a new precursor of thyrotropin-releasing hormone. FEBS Letters 293 292-296.

Burgus R, Dunn TF, Desiderio D, Ward DN, Vale W \& Guillemin R 1970 Characterization of ovine hypothalamic hypophysiotropic TSH-releasing factor. Nature 226 321-325.

Carr FE, Reid AH \& Wessendorf MW 1993 A cryptic peptide from thyrotropin-releasing hormone prohormone stimulates thyrotropin gene expression. Endocrinology 133 809-814.

Fliers E, Wiersinga WM \& Swaab DF 1998 Physiological and pathological aspects of thyrotropin-releasing hormone gene expression in the human hypothalamus. Thyroid 8 921-928.

Geris KL, D’Hondt E, Kühn ER \& Darras VM 1999 Thyrotropin-releasing hormone concentrations in different regions of the chicken brain and pituitary: an ontogenic study. Brain Research 818 260-266.

Geris KL, Berghman LR, Ladram A, Kühn ER, Darras VM \& Harvey S 2000 Modulation of the growth hormone-releasing activity of thyrotropin-releasing hormone in the chicken by its gene-related peptide preproTRH(160-169) (Ps4): enhanced somatostatinergic tone? Neuropeptides 34 51-57.

Guldenaar SE, Veldkamp B, Bakker O, Wiersinga WM, Swaab DF \& Fliers E 1996 Thyrotropin-releasing hormone gene expression in the human hypothalamus. Brain Research 743 93-101.

Harvey S 1990 Thyrotropin-releasing hormone: a growth hormone releasing factor. Journal of Endocrinology 125 345-358.

Harvey S \& Cogburn LA 1996 Cryptic peptides of prepro-TRH antagonize TRH-induced GH-secretion in chickens at extrapituitary sites. Journal of Endocrinology 151 359-364.

Harvey S, Hull KL, Geris KL, Cogburn LA, Bulant M \&Ladram A 1996 TRH-related peptides and GH secretion. VI International Symposium on Avian Endocrinology, Alberta, Canada. Abstract 6.04.

Hopp TP \& Woods KR 1981 Prediction of protein antigenic determinants from amino acid sequences. PNAS 78 3824-3828.

Jackson IMD, Wu P \& Lechan RM 1985 Immunohistochemical localization in the rat brain of the precursor for thyrotropin-releasing hormone. Science 229 1097-1099.

Józsa R, Korf HW, Csernus V \& Mess B 1988 Thyrotropin-releasing hormone (TRH)-immunoreactive structures in the brain of the domestic mallard. Cell and Tissue Research 251 441-449.

Kuchler K, Richter K, Trnovsky J, Egger R \& Kreil G 1990 Two precursors of thyrotropin-releasing hormone from skin of Xenopus laevis. Journal of Biological Chemistry 265 11731-11733.

Kuenzel WJ \& Masson M 1988 A Stereotaxic Atlas of the Brain of the Chick (Gallus domesticus). Baltimore, MD, USA: Johns Hopkins University Press.

Ladram A, Bulant M \& Nicolas P 1992 Characterization of receptors for thyrotropin-releasing hormone-potentiating peptide on rat anterior pituitary membranes. Journal of Biological Chemistry 267 25697-25702. 
Ladram A, Bulant M, Montagne JJ \& Nicolas P 1994 Distribution of TRH-potentiating peptide (Ps4) and its receptors in rat brain and peripheral tissues. Biochemical and Biophysical Research Communications 200 958-965.

Lechan RM, Wu P \& Jackson IMD 1986 Immunolocalization of the thyrotropin-releasing hormone prohormone in the rat central nervous system. Endocrinology 119 1210-1216.

Lee SL, Steward K \& Goodman RH 1988 Structure of the gene encoding rat thyrotropin-releasing hormone. Journal of Biological Chemistry 263 16604-16609.

Liao N, Bulant M, Nicholas P, Vaudry H \& Pelletier G 1988a Electron microscope immunocytochemical localization of thyrotropin-releasing hormone $(\mathrm{TRH})$ prohormone in the rat hypothalamus. Neuropeptides 11 107-110.

Liao N, Bulant M, Nicholas P, Vaudry H \& Pelletier G 1988 b Immuncytochemical distribution of neurons containing a peptide derived from thyrotropin-releasing hormone precursor in the rat brain. Neuroscience Letters 85 24-28.

McGivern RF, Rittenhouse P, Aird F, Van de Kar LD \& Redei E 1997 Inhibition of stress-induced neuroendocrine and behavioral responses in the rat by prepro-thyrotropin-releasing hormone-178-199. Journal of Neuroscience 17 4886-4894.

Nishiyama T, Kawano H, Tsuruo Y, Maegawa M, Hisano S, Adachi T, Daikoku S \& Suzuki M 1985 Hypothalamic thyrotropin-releasing hormone (TRH)-containing neurons involved in the hypothalamic-hypophyseal-thyroid axis. Light microscopic immunohistochemistry. Brain Research 345 205-218.

Ohide A, Ando H, Yanagisawa T \& Urano A 1996 Hydropathy profiles of predicted thyrotropin-releasing hormone precursors are highly conserved despite low similarity of primary structures. Journal of Neuroendocrinology 8 695-701.

Pekary AE 1998 Is Ps4 (prepro-TRH (160-169)) more than an enhancer for thyrotropin-releasing hormone? Thyroid $\mathbf{8}$ 963-968.
Redei E, Hilderbrand H \& Aird F 1995 Corticotropin release-inhibiting factor is preprothyrotropin-releasing hormone-(178-199). Endocrinology 136 3557-3563.

Richter K, Kawashima E, Egger R \& Kreil G 1984 Biosynthesis of thyrotropin releasing hormone in the skin of Xenopus laevis: partial sequence of the precursor deduced from cloned cDNA. EMBO Journal 3 617-621.

Roussel JP, Teresi S, Vaudry H \& Astier H 1994 A cryptic peptide of TRH prohormone inhibits TRH-induced GH release. Comptes Rendus de l'Académie des Sciences III 317 270-276.

Satoh T, Yamada M, Monden T, Iizuka M \& Mori M 1992 Cloning of the mouse thyrotropin-releasing hormone (TRH) cDNA and tissue distribution of its mRNA. Molecular Brain Research 14 131-135.

Schally AV, Redding TW, Boweres CY \& Barrett JF 1969 Isolation and properties of porcine thyrotropin-releasing hormone. Journal of Biological Chemistry 244 4077-4088.

Segerson TP, Hoefler H, Childers H, Wolfe HJ, Wu P, Jackson IM \& Lechan RM 1987 Localization of thyrotropin-releasing hormone prohormone messenger ribonucleic acid in rat brain in situ hybridization. Endocrinology 121 98-107.

Wallis JW, Aerts J, Groenen MAM, Crooijmans RPMA, Layman D, Graves TA, Scheer DE, Kremitzki C, Fedele MJ, Mudd NK et al. 2004 A physical map of the chicken genome. Nature 432 761-764.

Yamada M, Radovick S, Wondisford FE, Nakayama Y, Weintraub BD \& Wilber JF 1990 Cloning and structure of human genomic DNA and hypothalamic cDNA encoding human thyrotropinreleasing hormone. Molecular Endocrinology 4 551-556.

Received in final form 13 May 2005

Accepted 27 May 2005

Made available online as an Accepted Preprint

10 June 2005 